\title{
Synthesis and Dyeing Properties of Acid Dyes Derived from 1-amino-2-naphthol-4-sulphonic Acid
}

\author{
Olawale Olayinka Omotosho, Umar Salami Ameuru \\ Department of Polymer and Textile Engineering, Ahmadu Bello University, Zaria, Nigeria \\ Email address: \\ texttosh@gmail.com(O. O. Omotosho), usameuru@abu.edu.ng (U. S. Ameuru)
}

\section{To cite this article:}

Olawale Olayinka Omotosho, Umar Salami Ameuru. Synthesis and Dyeing Properties of Acid Dyes Derived from 1-amino-2-naphthol-4sulphonic Acid. World Journal of Applied Chemistry. Vol. 4, No. 4, 2019, pp. 63-68. doi: 10.11648/j.wjac.20190404.14

Received: August 29, 2019; Accepted: September 20, 2019; Published: October 28, 2019

\begin{abstract}
Natural dyes are derived from natural sources such as plants, animals and minerals. They are mostly nonsubstantive and can be applied on textiles materials by using mordants. Synthetic dyes are derived from organic or inorganic compound. They are cheaper, offer a vast range of new colour and impart better properties to textile materials. Synthetic dyes are widely used in industries amongst which textile processing industries are the major consumers. Acid dyes are soluble in water and it can be permanently fixed to the fibre with the addition of a weak acid and heat. A series of acid dyes were synthesized by diazotization of 1-amino-2-naphthol-4-sulphonic acid and coupled with various naphthalene derivatives such as 1-nitroso-2-naphthol, 2-nitroso-1-naphthol, 1-naphthol, 2-naphthol and N, N-dimethyl aniline. Visible absorption spectra of the dyes were examined in distilled water, ethanol and ethanol plus few drop of concentrated hydrochloric acid. The FT-IR analysis was determined to confirm the functional group present in the synthesized dye. The dye was applied on polyamide (Nylon) fabric and the colour parameters of dyed fabrics were examined to have good exhaustion between $\mathrm{pH} 3-4.5$ and more intense. After the dyeing process, the fabric was subjected to washing and light fastness. The remarkable degree of levelness and brightness of the synthesized acid dye on the nylon fabric is of good penetration, excellent affinity and very good fastness properties.
\end{abstract}

Keywords: Acid Dyes, FT-IR, UV Visible, Percentage Exhaustion, Fastness Properties

\section{Introduction}

Colourant is a term used for dyes and pigments [1]. A dye is a water-soluble substance from organic origin that when applied to a substrate provide colour by a process that alters any crystal structure of the coloured substances temporarily $[2,3]$ while a pigment is a coloured compound which is insoluble and from inorganic in origin [4]. But not all coloured compounds are textile dyes: some are only useful as indicators e.g. methyl orange, while some are used as stains or solvent dyes for colouring solvents such as petrol [5]. Dyes may be classified by their method of application to the substrate. They include acid dyes, direct dyes, reactive dyes, vat dyes, disperse dyes, azoic dyes, and several more types [6]. Natural dyes are mostly non-substantive and must be applied on textiles by the help of mordants, usually a metallic salt, having an affinity for both the colouring matter and the fibre [7]. Synthetic dyes are widely used in the textile, rubber product, paper, printing, colour photography, pharmaceuticals, cosmetics and many other industries, in which textile processing industries are the major consumers. Azo dyes represent the major and most versatile category of synthetic dyes [8-10]. A dye that contains sodium salts of a sulphonic acid group together with a phenolic group, are called acid azo dyes [11]. An acid dye is a dye that is typically applied to a textile at low $\mathrm{pH}$. These dyes can be applied to nylon, wool or silk not cotton fabrics in the $\mathrm{pH}$ range 3.0-7.0. The wet-fastness of these dyes varies from moderate to good and their light fastness is generally in the blue-scale range 5.0-6.0 reported according to $[12,13]$. Acid dyes are grouped based on their affinity, dyeing properties and chemical constitution of the dyes. There are different types of acid dyes reported by the researchers such as anthraquinone dyes, nitro dyes, triphenylmethane dyes and azo dyes [14-20]. Dyeing is the coloration of a textile material to a single solid shade. Dyeing is usually carried out in a dyebath containing water, dye and other chemicals (assistants) which assist dye absorption and retention on the 
fibre. The water serves to dissolve the dye and dyeing assistants. It is also absorbed by the fibre itself. The present study was focused on synthesis of acid dye derived from 1amino-2-naphthol-4-sulphonic acid and their dyeing properties on nylon fabrics.

\section{Materials and Methods}

\subsection{General Information}

All the chemicals used in the syntheses of the dyes were of analytical grade and were used without purification. Melting points were determined by the open capillary method. The visible absorption spectra were measured using JENWAY 6405 UV-visible spectrophotometer. IR spectra were recorded on a FT-IR 8400 spectrophotometer.

Synthesis of 3-hydroxy-4-((3-hydroxy-4nitrosonaphthalen-1-yl) diazenyl) naphthalene-1-sulfonic acid.

1-amino-2-naphthol-4-sulphonic acid $(2.39 \mathrm{~g}, 0.01 \mathrm{~m})$ was dissolved in $50 \mathrm{~cm}^{3}$ of distilled water containing $0.40 \mathrm{~g}$ of Sodium hydroxide. The solution was stand in an icebath, Sodium nitrite $(0.69 \mathrm{~g}, 0.01 \mathrm{~m})$ dissolved in $50 \mathrm{~cm}^{3}$ of distilled water was added drop wise for 30 minutes. An equivalent concentrated hydrochloric acid $(0.0125 \mathrm{~m})$ was added. The temperature of the amine dispersion was maintained at $0-5^{0} \mathrm{C}$. The reaction was allowed to continue for further 30 minutes with continuous stirring. Starch iodide paper turns blue-black to confirm that the diazotization is completed. 1-nitroso-2-naphthol $(1.73 \mathrm{~g}$, $0.01 \mathrm{~m}$ ) was dissolved in $50 \mathrm{~cm}^{3}$ of distilled water containing $0.40 \mathrm{~g}$ Sodium hydroxide in a beaker standing in ice-bath equipped with glass stirring rod and thermometer. The fresh diazonium salt previously prepared was then added drop wise to this solution for 30 minutes and stirred further for 1hour to produce the dye.

Synthesis of 3-hydroxy-4-((4-hydroxy-3nitrosonaphthalen-1-yl) diazenyl) naphthalene-1-sulfonic acid.

This was prepared in a similar manner in synthesis of 3-hydroxy-4-((3-hydroxy-4-nitrosonaphthalen-1-yl) diazenyl) naphthalene-1-sulfonic acid above, except 2nitroso-1-naphthol was used instead of 1-nitroso-2naphthol.

Synthesis of 3-hydroxy-4-((1-hydroxynaphthalen-2yl) diazenyl) naphthalene-1-sulfonic acid

It was prepared in a similar manner in synthesis of $3-$ hydroxy-4-((3-hydroxy-4-nitrosonaphthalen-1-yl) diazenyl) naphthalene-1-sulfonic acid above, except 1naphthol was used instead of 1-nitroso-2-naphthol.

Synthesis of 3-hydroxy-4-((2-hydroxynaphthalen-1yl) diazenyl) naphthalene-1-sulfonic acid.

This was also prepared in a similar manner in synthesis of 3-hydroxy-4-((3-hydroxy-4-nitrosonaphthalen-1-yl) diazenyl) naphthalene-1-sulfonic acid above, except 2naphthol was used instead of 1-nitroso-2-naphthol.

REACTION<smiles>Nc1c(O)cc(S(=O)(=O)O)c2ccccc12</smiles><smiles>[X]c1ccc2ccccc2c1[X]</smiles><smiles>[Y]c1cc(N=Nc2c(O)cc(S(=O)(=O)O)c3ccccc23)c2ccccc2c1[X]</smiles>

\begin{tabular}{|c|c|c|}
\hline Dye & $x$ & $Y$ \\
\hline a & $\mathrm{N}=\mathrm{O}$ & $\mathrm{OH}$ \\
\hline b & $\mathrm{OH}$ & $\mathrm{N}=\mathrm{O}$ \\
\hline c & $\mathrm{OH}$ & $\mathrm{H}$ \\
\hline$d$ & $\mathrm{H}$ & $\mathrm{OH}$ \\
\hline
\end{tabular}

Figure 1. Synthetic route for the dyes.

\subsection{Application of Synthesized Acid Dyes on Nylon Fabrics}

The dye baths were prepared from the dye $(1.0 \%$ on weight of fabric) with a $20 \%$ Glauber salt and $2 \%$ formic acid to a final liquor ratio of 50:1. The $\mathrm{pH}$ value of the bath was adjusted to $3-4.5$ with $5 \%$ acetic acid. The wetted nylon fabrics were immersed in each dye bath and dyed to the boiled for 90 minutes with continuous stirring of the dye bath. After dyeing, the fabrics were then removed, rinsed in cold water and then finally dried at room temperature [2123]. 


\subsection{Spectroscopy Analysis}

\subsubsection{Molar Extinction Coefficient}

The ratio of radiant power transmitted $(\mathrm{P})$ by a sample to the radiant power incident $(\mathrm{P} 0)$ on the sample is called the transmittance $\mathrm{T}$ :

$$
\mathrm{T}=\mathrm{P} / \mathrm{P} 0
$$

Absorbance (A), then, is defined as the logarithm (base 10) of the reciprocal of the transmittance:

$$
A=-\log T=\log (1 / T)
$$

In a spectrophotometer, monochromatic plane-parallel light enters a sample at right angles to the plane-surface of the sample. In these conditions, the transmittance and absorbance of a sample depends on the molar concentration (c), light path length in centimeters (L), and molar absorptivity $(\varepsilon)$ for the dissolved substance. The molar extinction coefficient (molar absorbance) of the synthesized dyes was calculated at each dye maximum $\left(K_{\max }\right)$ using this relation;

$$
A=\varepsilon c L
$$

\subsubsection{UV Spectroscopic Properties of the Dyes [24]}

The maximum absorption wavelength of the synthesized dyes was determined in three different solvents; distilled water, ethanol, ethanol with addition of few drop of concentrated hydrochloric acid respectively using a JENWAY $6405 \mathrm{UV}$-visible spectrophotometer in the visible wavelength of between $(400-800 \mathrm{~nm})$ using a glass cell of $1 \mathrm{~cm}$ path length. The instrument was first calibrated using each solvent as the blank. The result obtained was shown in Table 2 for the synthesized dyes in each solvent.

\subsubsection{The Infra-red Spectroscopic Properties of the Dyes} [25]

The synthesized dyes were further characterized with FTIR spectrophotometer to determine the functional group that present in the dyes.

\subsubsection{Optical Density Measurement (\% Exhaustion)}

The $\%$ exhaustion was determined by measuring the optical densities of the dye solutions before and after dyeing, at the maximum wavelength $\left(K_{\max }\right)$ of each dye, using JENWAY $6405 \mathrm{UV} /$ visible spectrophotometer and the $\%$ exhaustion was calculated using this expression;

$$
\% \text { Exhaustion }=\frac{O D 1-O D 2}{O D 1} \times 100
$$

$\mathrm{OD}_{1}$ and $\mathrm{OD}_{2}$ are the optical densities of the solution before and after dyeing respectively. The results of $\%$ exhaustion obtained were represented in Figure 2.

\subsubsection{Washing Fastness Test}

Using ISO test number 3 washing method, a soap solution containing $5 \mathrm{~g} / 1$ of soap and $2 \mathrm{~g} / \mathrm{l}$ of soda ash $\left(\mathrm{NaCO}_{3}\right)$ was prepared with distilled water to a liquor ratio of 50:1. A $5 \times$ $2 \mathrm{~cm}$ of the dyed fabric was taken and then placed in between two adjacent pieces of undyed fabric (one was nylon fabric and the other wool fabric) and then stitched together. The sample prepared was immersed in soap solution above and then boiled at $60^{\circ} \mathrm{C}$ for 30 minutes. After soaping treatment, the sample was removed; rinse twice in cold water, squeeze and air dry at a temperature not exceeding $60^{\circ} \mathrm{C}$. In this test, change in colour of the dyed fabric and also stain of colour observed on the adjacent fabric was assessed with grey scales.

\subsubsection{Light Fastness Test}

Light fastness test were carried out using the standard procedures as contained in ISO 105. This test measures the resistance to fading of dyed fabric when exposed to day light. The test sample was exposed alongside with blue wool scale to day light for 72 hours, after which, the sample was then removed and compared the change with original unexposed samples.

\section{Results}

The results of the acid dye synthesized, their characterization and application on Nylon fabric were summarized in the table and figure below.

Table 1. Physical Characteristics of the Synthesized Dyes.

\begin{tabular}{llllll}
\hline Dyes & Molar mass $(\mathrm{g} / \mathrm{mol})$ & Melting point $\left({ }^{\circ} \mathrm{C}\right)$ & $\%$ Yield & Colour of the crystal Structure of the dyes \\
\hline $\mathrm{A}$ & 423 & $105-107$ & 68.9
\end{tabular}




\begin{tabular}{|c|c|c|c|c|c|}
\hline Dyes & Molar mass (g/mol) & Melting point $\left({ }^{\circ} \mathrm{C}\right)$ & $\%$ Yield & Colour of the crystal & Structure of the dyes \\
\hline B & 423 & $108-110$ & 85.5 & Yellowish brown & \\
\hline $\mathrm{C}$ & 394 & 107-109 & 34.9 & Dark brown & \\
\hline D & 394 & $100-101$ & 81.9 & Reddish brown & \\
\hline $\mathrm{E}$ & 370 & 104-106 & 50.7 & Dark brown & \\
\hline
\end{tabular}

Table 2. The UV Spectroscopic Properties of the Dyes.

\begin{tabular}{|c|c|c|c|c|c|}
\hline Dyes & $\begin{array}{l}\text { Molar extinction coefficient } \times \\
10^{4} \mathrm{~L} \mathrm{~mol}^{-1} \mathbf{c m}^{-1} \text { in Water }\end{array}$ & $\begin{array}{l}\boldsymbol{K}_{\max }(\mathrm{nm}) \text { in distilled } \\
\text { Water }\end{array}$ & $\begin{array}{l}\Lambda_{\max }(\mathrm{nm}) \text { inm } \\
\text { Ethanol }\end{array}$ & $\begin{array}{l}\kappa_{\max }(\mathrm{nm}) \text { in Ethanol plus } \\
\text { a drop of Conc. Hel }\end{array}$ & $\begin{array}{l}\text { Change in } \Lambda_{\max }(\mathrm{nm}) \text { of }(\text { Ethanol }+\mathrm{HCl}) \\
\text { minus (Ethanol) }\end{array}$ \\
\hline A & 1.114 & 410 & 495 & 510 & +15 \\
\hline B & 1.951 & 415 & 420 & 445 & +25 \\
\hline $\mathrm{C}$ & 1.633 & 475 & 440 & 450 & +10 \\
\hline D & 1.126 & 410 & 470 & 490 & +20 \\
\hline E & 2.118 & 455 & 475 & 485 & +10 \\
\hline
\end{tabular}

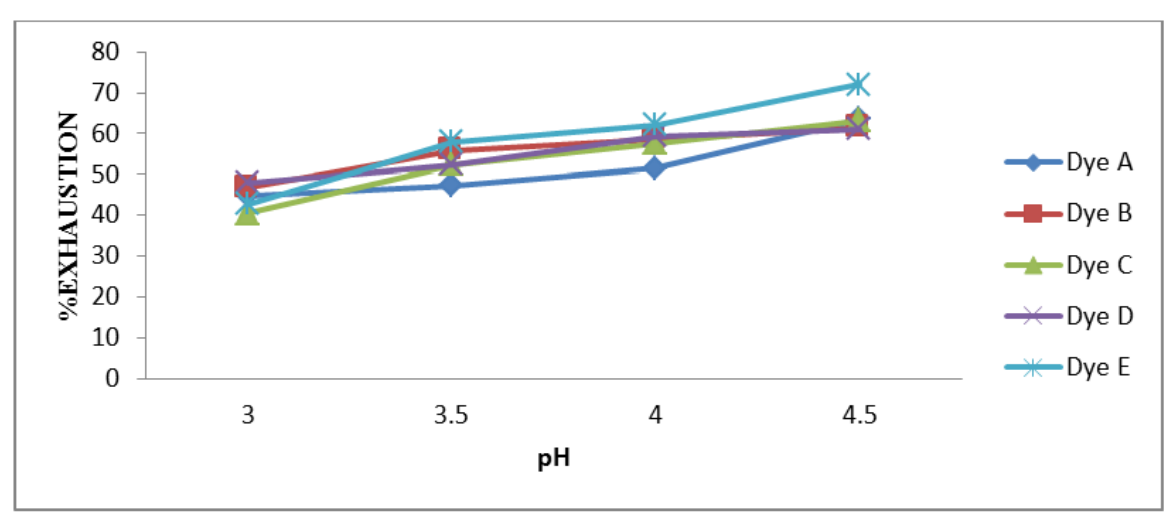

Figure 2. Percentage Exhaustion against the $\mathrm{pH}$.

\section{Discussion}

Acid dyes (A-E) were synthesized by producing diazonium salt of 1-amino-2-naphthol-4-sulphonic acid and coupled with the following coupling components; 1-nitroso2-naphthol, 2-nitroso-1-naphthol, 1-naphthol, 2-naphthol and $\mathrm{N}$, N-dimethyl aniline. The detail on physical properties of the synthesized dyes is shown in Table 1.
The visible absorption maxima of the dyes were observed in different solvents such as distilled water, ethanol and ethanol plus a drop of concentrated hydrochloric acid. The results are shown in Table 2 . The $\kappa_{\max }$ of the synthesized dyes were shifted significantly at various solvent.

Dye A absorbed at $410 \mathrm{~nm}$ in distilled water, $495 \mathrm{~nm}$ in ethanol and 510nm in ethanol plus a drop of concentrated hydrochloric acid and dye B absorbed at $415 \mathrm{~nm}$ in distilled water, $420 \mathrm{~nm}$ in ethanol, and $445 \mathrm{~nm}$ in ethanol plus a drop of 
concentrated hydrochloric. These means that dye A shows hypsochromic shift by $5 \mathrm{~nm}$ in distilled water and a bathochromic shift by $75 \mathrm{~nm}$ in ethanol, and bathochromic shift by $65 \mathrm{~nm}$ in ethanol plus a drop of concentrated hydrochloric acid. Dye A absorbed at $495 \mathrm{~nm}$ in ethanol when compared with dye B (420nm) in the same solvent which indicate bathochromic shift by $75 \mathrm{~nm}$ which may be attributed to change in positions of $\mathrm{N}=\mathrm{O}$ and $\mathrm{O}=\mathrm{H}$ in the dyes respectively.

Dye $C$ absorbed at $475 \mathrm{~nm}$ in distilled water, $440 \mathrm{~nm}$ in ethanol, and $450 \mathrm{~nm}$ in ethanol plus a drop of concentrated hydrochloric acid. Dye D absorbed at $410 \mathrm{~nm}$ in distilled water, 470nm in ethanol, and 490nm in ethanol plus a drop of concentrated hydrochloric acid. Dye $\mathrm{C}$ shows bathochromic shift by $65 \mathrm{~nm}$ in distilled water, a hypsochromic shift by $30 \mathrm{~nm}$ in ethanol, and hypsochromic shift by $40 \mathrm{~nm}$ in ethanol plus a drop of concentrated hydrochloric acid.

Dye E absorbed at $455 \mathrm{~nm}$ in distilled water, $475 \mathrm{~nm}$ in ethanol, and $485 \mathrm{~nm}$ in ethanol plus a drop of concentrated hydrochloric acid. It shows that dye $\mathrm{E}$ is hypsochromic by $40 \mathrm{~nm}, 55 \mathrm{~nm}$, and 40nm when compared with dye B which may be attributed to methyl group that is present in dye E.

As represented graphically in Figure 2 for the synthesized dyes, percentage exhaustion increases as the $\mathrm{pH}$ of the dye bath increases. At $\mathrm{pH}$ of 3.0, their percentage exhaustions was $44.8 \%, 46.8 \%, 40.4 \%, 47.9 \%, 42.8 \%$ and at $\mathrm{pH}$ of 3.5 , they increases to $47 \%, 55.9 \%, 52.3 \%, 52.3 \%, 57.9 \%$. Moreover at $\mathrm{pH}$ of 4.0 , they have $51.5 \%, 58.7 \%, 57.4 \%$, $59.3 \%, 62.2 \%$ and finally at $\mathrm{pH}$ of 4.5 , the percentage exhaustion increases to $63.5 \%, 61.5 \%, 63 \%, 60.9 \%, 72 \%$ respectively.

Table 3. Fastness Properties of the Synthesized Dyes.

\begin{tabular}{|c|c|c|c|c|}
\hline \multirow{2}{*}{ Dyes } & \multirow{2}{*}{ PH } & \multicolumn{2}{|c|}{ Wash Fastness Rating } & \multirow{2}{*}{$\begin{array}{l}\text { Staining } \\
\text { adjacent }\end{array}$} \\
\hline & & Light Fastness & Change in shade & \\
\hline \multirow{4}{*}{ A } & 3.0 & 4 & $4-5$ & $1-2$ \\
\hline & 3.5 & 7 & $4-5$ & $1-2$ \\
\hline & 4.0 & 7 & 4 & 2 \\
\hline & 4.5 & 7 & $4-5$ & $1-2$ \\
\hline \multirow{4}{*}{ B } & 3.0 & 4 & $4-5$ & $1-2$ \\
\hline & 3.5 & 5 & $4-5$ & $1-2$ \\
\hline & 4.0 & 3 & 4 & 2 \\
\hline & 4.5 & 3 & 4 & 2 \\
\hline \multirow{4}{*}{$\mathrm{C}$} & 3.0 & 3 & 4 & 2 \\
\hline & 3.5 & 3 & $4-5$ & $1-2$ \\
\hline & 4.0 & 3 & $4-5$ & $1-2$ \\
\hline & 4.5 & 4 & $4-5$ & $1-2$ \\
\hline \multirow{4}{*}{$\mathrm{D}$} & 3.0 & 4 & $3-4$ & $2-3$ \\
\hline & 3.5 & 5 & $4-5$ & $1-2$ \\
\hline & 4.0 & 3 & $3-4$ & $2-3$ \\
\hline & 4.5 & 3 & $3-4$ & $2-3$ \\
\hline \multirow{4}{*}{ E } & 3.0 & 3 & $4-5$ & $1-2$ \\
\hline & 3.5 & 3 & $4-5$ & $1-2$ \\
\hline & 4.0 & 3 & $4-5$ & $1-2$ \\
\hline & 4.5 & 3 & 4 & 2 \\
\hline
\end{tabular}

The Table 3 summarized the wash fastness rating of the synthesized dyes using ISO test number 3 washing procedure. The results were obtained using grey scale rating $1-5$. The synthesized dyes has scale rating of good to very good (i.e. 4-5) and the stain observed on wool and nylon used as adjacent fabric is insignificant. Also, light fastness properties of the synthesized dyes rating between good to excellent (3-7) using blue scale and found to depend on the influence of the substituents which changes the electron density around the azo group.

\section{Conclusion}

1-amino-2-naphthol-4-sulphonic acid was diazotized and coupled with 1-nitroso-2-naphthol, 2-naphthol; N, Ndimethyl aniline, 1-naphthol and 2-nitroso-1-naphthol to produced acid dyes in good yield. FT-IR spectrophotometers were used to confirm the functional group of the synthesized dyes. Other physical and chemical properties of the synthesized dyes such as UV-visible, melting point and percentage yield were determined. The dyes gave good percentage exhaustion when applied on nylon fabric $(40.4 \%$ $72 \%$ ). The wash fastness properties was very good rating from 4-5 while the light fastness shows fairly good to very good rating from 3-7 on nylon fabric respectively.

\section{Acknowledgements}

The authors want to appreciate all the staff of department of Polymer and Textile engineering for supplying of the reagents and all the materials used for this research, multiuser laboratory in Chemistry department and NARIT Zaria branch for the using of their equipment during characterization of the synthesized dyes. Mr. Simeon Ogunshola Omotosho and Mrs. Alice Modupe Omotosho for their financial assistance rendered during the research.

\section{References}

[1] Pereira, L. and Aives, M. M. Dyes; Enviromental Impact and Remediation. University of Minho, Braga, Portugal. 2012, $110-115$.

[2] Kirk-Othmer. Encyclopedia of Chemical Technology, v. 7, 5th Edition. Wiley-Interscience, 2004.

[3] Bafana A, Devi SS, Chakrabarti T. Azo dyes: past, present and the future. Environmental Reviews, 2011, (19): 350-370.

[4] Hofenk, J. H. Graaff. The Colourful Past. Origins, Chemistry and Identification of natural Dyestuffs, London, 2004, 8-10.

[5] Nkeoye, P. O. Introductory Textiles; for Home Economists, Students of Art and Beginners Generally. Ahmadu Bello University Press Ltd, Zaria. 2009, 47-54.

[6] Gregory, P. The Chemistry and Application of Dyes. Plenum Press New-York. 1990, 150-187.

[7] A. K. Samanta, P. Agarwal, Application of natural dyes on textiles, Indian Journal of Fibre and Textile Research, 2009, (34): 384-399.

[8] Keharia, H., Patel, H., Madamwar, D. Decolorization Screening of Synthetic dyes by anaerobic methanogenic Sludge using batch decolourization assay. World Journal of Microbiology Biotechnology, 2004, (20): 365-370. 
[9] Raffi F., Hall J. D. and Cerniglia C. E. Mutagenicity of azo dyes used in foods, drugs and cosmetics before and after reduction by Clostridium species from the human intestinal tract. Food and Chemical Toxicology. 1997, (35): 897-901.

[10] H. Keharia, D. Madamwar, Bioremediation concepts for treatment of dye containing wastewater: a review, India Journal of Experimental, 2003, (41): 1068-1075.

[11] Dixit, B. C., Patel, H. M., Dixit, R. B., Desal, D. J. Synthesis, characterization and dyeing assessment of novel acid azo dyes and mordent acid azo dyes basesd on 2-hydroxy-4methoxybenzophenone on wool and silk fabrics. Journal of the Serbian Chemical society, 2010, 75 (5): 605-614.

[12] Booth, G. Dyes, General Survey. Ullmann's Encyclopedia of Industrial Chemistry. Weinheim: Wiley-VCH, 2000, doi: 10.1002/14356007.a09_073.

[13] D. M. Nunn, the Dyeing of Synthetic-Polymer and Acetate Fibres, Dyers Co. Publications Trust, 1979.

[14] Foris A. In: Venkataraman K, editor. NMR spectroscopy of synthetic dyes, in the analytical chemistry of synthetic dyes. New York: John Wiley and Sons, 1977, 217.

[15] Venkataraman K. The chemistry of synthetic dyes, vol. II. New York and London: Academic Press, 1952.

[16] Szadowski J, Rzybylski C. Relationships between the structures of nitrodiphenylamine derived monoazo acid dyes and their spectroscopic and fastness properties. Dyes Pigments, 1984, (5): 49.
[17] Mclellan JM, Somerville MA. Molecular resist compositions, methods of patterning substrates using the compositions and process products prepared there from. 2009, US 2009/0311484.

[18] Gaspar B, Hills B, Dreyfuss PD, Nuys V. Acid azo dyes, 1948, US 2612496.

[19] Bornengo G, Merlo F, Paffoni C. Water-soluble acid azo dye, 1980, US 4187218

[20] Stohr B, Nickel, H. Piperazinyl-triazinylnaphtholsulphonic acid azo dyes, 1985, US 4544737.

[21] Ameuru, U. S. Synthesis, Characterization and the Dyeing Properties of Nitrosonaphthol Dyes on Tanned Leathers. Unpublished Thesis, Department of Textile Science and Technology, Ahmadu Bello University, Zaria 2009.

[22] Aspland, J. R., Anionic Dyes and their Application to Ionic Fibre. Dyeing Nylon with Acid Dyes, School of Textiles, Clemson University, South Carolina 1993, 15-20.

[23] Bello, K. A., Textile Chemical Processing 11. Department of Textile Science and Technology, Ahmadu Bello University, Zaria 2013.

[24] Ingamells W. Colour for Textiles, A user's Handbook. SDC, 1993, 10-11.

[25] Silverstein, R. M. and Webster, F. X. Spectrometric Identification of Organic Compounds. 6th Edition, John Wiley and Sons, Hoboken. 1997, 71-103. 